\title{
Políticas públicas de educação ambiental e processos de mediação em escolas de Ensino Fundamental
}

\author{
Public policies for an Environmental Education \\ and mediation processes in elementary schools
}

\author{
Maria Aparecida Arnaldo ${ }^{1}$. \\ Luiz Carlos Santana ${ }^{1}$ \\ https://orcid.org/0000-0003-4973-2483
}

\begin{abstract}
Resumo: Este artigo analisa a escola como espaço de mediação das políticas públicas de educação ambiental e os processos pelos quais essa mediação ocorre. A partir de questionários, foram selecionadas sete escolas de Ensino Fundamental I de um município paulista, investigadas por meio de entrevistas, observações e análises de documentos. Os resultados apontaram que as escolas investigadas desenvolvem processos em que as mediações das políticas públicas de educação ambiental são manifestadas ao: envolver a transversalidade, a interdisciplinaridade e o trabalho com projetos no desenvolvimento da educação ambiental; compreender a educação ambiental como possibilidade de conscientização dos sujeitos sobre questões ambientais; considerar os alunos como multiplicadores dos conhecimentos sobre as questões ambientais; procurar integrar a comunidade utilizando a temática ambiental. Entretanto, observou-se que esses processos são permeados, predominantemente, por concepções pragmáticas de educação ambiental, que deixam, muitas vezes, de vislumbrar transformações nas estruturas da sociedade.
\end{abstract}

Palavras-chave: Educação ambiental. Políticas públicas. Mediação. Ensino fundamental.

\begin{abstract}
This article sees the school as a space for mediation in public policies for environmental education and the processes by which this mediation takes place. After the questionnaires, we selected seven elementary schools of a city in São Paulo state, which were investigated through interviews, observation and document analysis. The results showed that by: involving crosscutting, interdisciplinary and project work in the development of environmental education; understanding environmental education as a possibility of awareness of the subjects on environmental issues; considering students as multipliers of knowledge about environmental issues and; integrating the community using the environmental theme, the investigated schools developed processes where the mediations of public environmental education policies are manifested. It was noted, however, that such processes, predominantly showing, pragmatic conceptions of environmental education, lead several times, to beliefs in changes in the structures of society.
\end{abstract}

Keywords: Environmental education. Public policy. Mediation. Public school.

\footnotetext{
1 Universidade Estadual Paulista (Unesp), Instituto de Biociências, Programa de Pós-graduação em Educação, Rio Claro, SP, Brasil. E-mail: <maparnaldo@gmail.com>.
} 


\section{Introdução}

Nas décadas de 1960 e 1970 do século XX, a procura por soluções para os problemas ambientais, que se evidenciaram com intensidade, apontou o processo educativo como parte das propostas de soluções para resolver ou, quando isso não for possível, amenizar tais problemas.

A associação do processo educativo ao enfrentamento dos problemas ambientais sugere que, de modo geral, a procura por soluções para a reversão dos problemas ambientais envolve um trabalho de divulgação, conscientização, construção de saberes, revisão de valores e atitudes e de efetiva transformação social, e esse trabalho assinala a educação como condição indispensável a isso.

Assim, a educação ambiental "surgiu no contexto de uma crise ambiental reconhecida no final do século XX, e estruturou-se como fruto da demanda para que o ser humano adotasse uma visão de mundo e uma prática social capazes de minimizar os impactos ambientais" (LAYRARGUES; LIMA, 2014, p. 26).

É importante observar que há diversos caminhos para se compreender, desenvolver e realizar a educação ambiental.

De acordo com Loureiro (2005, p. 1.475), desde quando foram identificadas as primeiras experiências relacionadas à educação ambiental, na década de 1970, começaram a se definir dois grandes blocos "que historicamente alcançaram maior destaque no cenário da Educação Ambiental, seja pela proximidade com as discussões políticas da área, pela tradição na educação ou pela afinidade com teorias que obtiveram maior acúmulo no debate ambientalista".

Um desses blocos, denominado de conservador ou comportamentalista, apresenta como características centrais:

- compreensão naturalista e conservacionista da crise ambiental;

- educação entendida em sua dimensão individual, baseada em vivências práticas;

- despolitização do fazer educativo ambiental, apoiando-se em pedagogias comportamentalistas ou alternativas de cunho místico;

- baixa problematização da realidade e pouca ênfase em processos históricos;

- foco na redução do consumo de bens naturais, descolando essa discussão do modo de produção que a define e situa;

- diluição da dimensão social na natural, faltando entendimento dialético da relação sociedade-natureza [...];

- responsabilização pela degradação posta em um homem genérico, fora da história, descontextualizado social e politicamente (LOUREIRO, 2005, p. 1.475).

O outro bloco, denominado de transformador, crítico ou emancipatório apresenta entre suas principais características:

- busca da realização da autonomia e liberdades humanas em sociedade, redefinindo o modo como nos relacionamos com a nossa espécie, com as demais espécies e com o planeta; 
- politização e publicização da problemática ambiental em sua complexidade;

- convicção de que a participação social e o exercício da cidadania são práticas indissociáveis da Educação Ambiental;

- preocupação concreta em estimular o debate e o diálogo entre ciências e cultura popular, redefinindo objetos de estudo e saberes;

- indissociação no entendimento de processos como: produção e consumo; ética, tecnologia e contexto socio-histórico; interesses privados e interesses públicos;

- busca de ruptura e transformação dos valores e práticas sociais contrários ao bem-estar público, à equidade e à solidariedade. (LOUREIRO, 2005, p. 1.476).

No contexto neoliberal das sociedades contemporâneas ocidentais, em que os valores e a lógica são impostos pela economia do mercado, Layrargues e Lima (2014) consideram que a macrotendência pragmática da educação ambiental, que é uma derivação da conservacionista, ganhou impulso. Essa macrotendência, segundo os autores, acolhe as correntes de Educação para o Desenvolvimento Sustentável e para o Consumo Sustentável, com práticas relacionadas a mudanças superficiais, comportamentais e tecnológicas voltadas à economia de energia e de água, à reciclagem de resíduos sólidos, ao mercado de carbono, entre outras.

Segundo Layrargues e Lima (2014) há, no Brasil, atualmente, três macrotendências como modelos políticos pedagógicos para a educação ambiental: a Conservacionista, a Pragmática e a Crítica. Para eles, "cada uma dessas macrotendências contempla uma ampla diversidade de posições mais ou menos próximas do tipo ideal considerado" (LAYRARGUES; LIMA, 2014, p. 30).

Compreendemos que a perspectiva crítica da educação ambiental, embora não hegemônica, é a mais coerente com o enfrentamento da crise socioambiental, articulando a ela questões políticas, desigualdades sociais e a injustiça socioambiental. E concordamos com Guimarães (2004, p. 32), que sugere que essa concepção de educação ambiental, num exercício de cidadania "se propõe a desvelar a realidade, para, inserindo o processo educativo nela, contribuir na transformação da sociedade atual, assumindo de forma inalienável a sua dimensão política".

A macrotendência crítica, segundo Layrargues e Lima (2014, p. 33): “Apoia-se com ênfase na revisão crítica dos fundamentos que proporcionam a dominação do ser humano e dos mecanismos de acumulação do Capital, buscando o enfrentamento político das desigualdades e da injustiça socioambiental". Compreendemos, assim, que a educação ambiental crítica se direciona à superação das relações de dominação presentes na sociedade moderna, e se constitui num importante elemento para buscar possibilidades de enfrentamento da crise socioambiental.

A superação de tal crise passa, necessariamente, pelo aprendizado de uma nova relação dos homens entre si e destes com a natureza, o que implica em mudanças fundamentais de tais relações. Gonçalves (2006, p. 25) aponta que a oposição homem-natureza é uma característica do pensamento do mundo ocidental: "A natureza se define, em nossa sociedade, por aquilo que se opõe à cultura. A cultura é tomada como algo superior e que conseguiu controlar e dominar a natureza".

Esse mesmo autor destaca que, no âmbito da classe dominante, há um processo de naturalização das relações sociais, escamoteando que essas relações são fundamentadas em conflitos e disputas e, portanto, não são naturais. Assim: 


\begin{abstract}
São íntimas as relações que se estabelecem entre a concepção de que o homem deve dominar a natureza e a ideia de que o homem deve dominar outros homens (mulheres, crianças, adolescentes, velhos, negros, índios, homossexuais, operários, camponeses, etc.) - na medida em que esses últimos são socialmente vistos como seres da natureza (GONÇALVES, 2006, p. 134-135).
\end{abstract}

Nesse sentido, são necessárias transformações profundas no modo de pensamento e nas relações estabelecidas em nossa sociedade atual.

Sorrentino et al. (2005) afirmam que a transformação social, da qual a educação ambiental trata, tem como objetivo a superação de desigualdades e injustiças sociais e ambientais. Segundo os autores:

Cumpre à educação ambiental fomentar processos que impliquem o aumento do poder das maiorias hoje submetidas, de sua capacidade de autogestão e o fortalecimento de sua resistência à dominação capitalista de sua vida (trabalho) e de seus espaços (ambiente) (SORRENTINO et al., 2005, p. 287).

A ação política por meio da educação ambiental é possível, de acordo com Sorrentino et al. (2005). Para eles, a "educação ambiental, em específico, ao educar para a cidadania, pode construir a possibilidade da ação política, no sentido de contribuir para formar uma coletividade que é responsável pelo mundo que habita” (SORRENTINO et al., p. 287).

Vale ressaltar que a ação política necessária para as mudanças pretendidas precisa, também, contar com propostas e ações do Estado e de governos, no sentido de fortalecer a sociedade civil, buscando atender e resolver suas demandas.

Quanto à nossa compreensão de sociedade civil, nos apoiamos em Gramsci (2001, p. 20-21) que aponta:

Por enquanto, podem-se fixar dois grandes "planos" superestruturais: o que
pode ser chamado de "sociedade civil" (isto é, o conjunto de organismos
designados vulgarmente como "privados") e o da "sociedade política ou Es-
tado", planos que correspondem, respectivamente, à função de "hegemonia"
que o grupo dominante exerce em toda a sociedade e àquela de "domínio
direto" ou de comando, que se expressa no Estado e no governo "jurídico".

Desse modo, com base no pensamento de Gramsci (2001), consideramos que a sociedade civil, apesar de ser constituída por instituições não estatais, cumpre um papel fundamental no sentido de transmitir os valores dominantes, produzir o consenso, a hegemonia das classes dominantes, tornando-se, assim, espaço de lutas e de disputas.

Para que as demandas que surgem das diversas necessidades da sociedade sejam atendidas, torna-se necessário que sejam elaboradas e desenvolvidas políticas públicas que, segundo Höfling (2001) devem demandar a participação social por meio de suas representações.

Dentre as demandas sociais, encontramos aquelas referentes à temática ambiental. Assim, podemos afirmar que a educação ambiental pode ser, também, identificada no âmbito 
da política pública, pois: "Uma política pública representa a organização da ação do Estado para a solução de um problema ou atendimento de uma demanda específica da sociedade" (SORRENTINO et al., 2005, p. 290).

No Brasil, em nível federal, temos a Política Nacional de Educação Ambiental (PNEA), Lei $n^{\circ} 9.795$, de 27 de abril de 1999, que, em seu artigo 10, considera que a educação ambiental deve ser desenvolvida em todos os níveis e modalidades do ensino formal como uma prática integrada e permanente, e que a mesma não deve ser uma disciplina específica do currículo (BRASIL, 1999).

No Estado de São Paulo, a Lei no 12.780, de 30 de novembro de 2007, que institui a Política Estadual de Educação Ambiental, foi criada de acordo com os princípios e objetivos da PNEA, reforçando, no parágrafo único de seu artigo 16, a necessidade da transversalidade da educação ambiental em todos os níveis de ensino (SÃO PAULO, 2007).

No município de Rio Claro, SP, a Política de Educação Ambiental foi instituída pela Lei Municipal no 4.026, de 26 de fevereiro de 2010, que, em seu artigo $1^{\circ}$, também considera a educação ambiental como uma prática educativa a ser desenvolvida de maneira transversal e interdisciplinar. A referida lei afirma, ainda, nos demais artigos, que os planos de trabalho das escolas deverão estabelecer programação de atividades relativas à educação ambiental e enfatizar a observação da natureza, dos problemas e experiências práticas, a fim de que os conceitos possam ser colocados em prática (RIO CLARO, 2010).

Observamos, então, que as políticas públicas, em qualquer âmbito da federação, afirmam que a educação ambiental deve ser desenvolvida nas instituições formais de ensino de maneira interdisciplinar para superar o trabalho pedagógico fragmentado, permitindo ao aluno associar, mais facilmente, o conhecimento desenvolvido no ambiente escolar às aplicações de sua vivência.

Entendemos que essas legislações integrantes das políticas públicas, ao indicarem a necessidade de que a educação ambiental seja também desenvolvida no ensino formal, ou seja, na educação escolar, buscam inserir a educação ambiental no processo de formação dos indivíduos, compreendendo a escola como "forma principal e dominante de educação" (SAVIANI, 2015, p. 35).

No contexto escolar, muitas são as práticas e relações que se estabelecem, constituindo um espaço em que muitos conhecimentos são desenvolvidos e ações efetivadas. Nas ações cotidianas, nas relações entre as pessoas, nos procedimentos e práticas pedagógicas desenvolvidas pelos diversos atores em contato com a realidade e seu movimento, ocorrem mediações que podem envolver os conhecimentos, os conceitos, as ideias, as ações e as práticas presentes no espaço da escola.

Compreendendo a educação como mediação, Cury (2000), Saviani (2015) e Severino (2001) entendem que ela pode contribuir tanto para que a ordem social seja mantida quanto para que seja transformada.

Cury (2000, p. 66) afirma que a educação, por meio da categoria da mediação, pode revelar-se "como um elo existente capaz de viabilizar uma estruturação ideológica para um determinado modo de produção, que, por sua vez, tende a assegurar a dominação de classe pela hegemonia". No entanto, o autor pondera que a educação não é local de uma reprodução somente da ideologia dominante, pois a hegemonia inclui, também, elementos da classe dominada. Nesse sentido, considera que a educação como mediação tanto pode contribuir para que a ordem social seja mantida, quanto para que seja transformada: 


\begin{abstract}
Na medida em que a educação se torna um meio de uma expressão coerente e adequada de uma concepção de mundo que se oponha à mistificação, ela é, antes de tudo, lugar de luta pela hegemonia de classe, pois a efetividade de uma dominação absoluta eliminaria a contradição, condição básica da sociedade de classes. A educação como mediação tanto funciona, embora em graus diferentes, para a afloração da consciência, como para impedi-la, tanto para difundir, como para desarticular (CURY, 2000, p. 66).
\end{abstract}

Severino (2001, p. 75), ao conceber a educação como mediação, também destaca esse caráter contraditório que pode, ao mesmo tempo em que reforça a dominação na sociedade das ideologias e das relações sociais, criticar e atuar para superar seus "conteúdos ideológicos", auxiliando na resistência à dominação.

É verdade que a educação não atua como a grande alavanca da transformação social, pois sua ação é mediada pelas referências simbólicas. Mas a transformação da sociedade também não se dará sem mudanças na esfera simbólica. Por isso, a educação ocupa lugar importante no conjunto desse processo. As mudanças econômicas e políticas pressupõem mudanças profundas e simultâneas na esfera ideológica. É que as práticas reais (produtiva, política e simbolizadora) também são mediadoras da existência histórica dos homens e interfaces de um único processo geral (SEVERINO, 2001, p. 75-76).

A educação, ao mediar as práticas reais, pode, gradativamente, ocasionar as mudanças necessárias na esfera ideológica, que auxiliam nas transformações da sociedade de classes. $\mathrm{Na}$ pedagogia histórico-crítica, segundo Saviani (2015, p. 37), durante os momentos intermediários na mediação educativa no interior da prática social (problematização, instrumentação e catarse), o ponto culminante do processo educativo se dá "quando ocorre a efetiva incorporação dos instrumentos culturais, transformados em elementos ativos de transformação social”.

Consideramos que a escola, por ser o principal espaço onde a educação formal ocorre, bem como o espaço onde grande número das pessoas passam parte significativa do tempo de suas vidas, pode ser, portanto, espaço de mediação de vários elementos que influenciam e, de certa forma, delineiam a sociedade. Um desses elementos pode ser, inclusive, as políticas públicas entendidas como propõe Höfling (2001, p. 31) “o Estado implantando um projeto de governo, através de programas, de ações voltadas para setores específicos da sociedade”.

\title{
Políticas Públicas e mediação
}

As políticas públicas de educação ambiental, que em nossa compreensão devem contemplar as necessidades sociais que as originaram, ou seja, demandas referentes às questões ambientais, apresentam em seu conteúdo orientações e concepções que norteiam e embasam o desenvolvimento da educação ambiental.

Inferimos que as políticas públicas de educação ambiental se manifestam nas escolas por meio de processos que são permeados por concepções, princípios, objetivos ou, ainda, 
indicações sobre o modo de realização de trabalho com educação ambiental, explicitados nas políticas públicas. Assim, as escolas podem ser consideradas espaços de mediação das políticas públicas de educação ambiental.

Ao considerarmos a escola como principal espaço de realização do ensino formal, a consideramos, também, como espaço de mediação de políticas públicas de educação ambiental, a partir do pressuposto de que há, nessas políticas públicas, a orientação do desenvolvimento da educação ambiental.

O presente artigo é resultado de uma dissertação de mestrado em que se realizou uma pesquisa de natureza qualitativa, na qual buscamos analisar a escola como espaço de mediação das políticas públicas de educação ambiental e os processos pelos quais essa mediação ocorre.

\section{A educação ambiental na escola e a escola como espaço de mediação}

Tratando da escola numa perspectiva crítica, Saviani (2003, p. 14) a define como "uma instituição cujo papel consiste na socialização do saber sistematizado". O autor destaca que "a escola diz respeito ao conhecimento elaborado e não ao conhecimento espontâneo; ao saber sistematizado e não ao saber fragmentado; à cultura erudita e não à cultura popular"'

Para Tozoni-Reis e Janke (2014, p. 115):

Isso significa afirmar que a especificidade da educação escolar está em promover a consciência dos educandos para a compreensão e a transformação da realidade. Então, o que é próprio da escola é a garantia da transmissão - não mecânica, mas ativa - do saber elaborado pela cultura.

Compreendemos, com isso, que a escola tem como função aproximar os educandos do saber historicamente construído pela sociedade, auxiliando-os para que possam melhor entender que mudanças sociais são possíveis e, ao proporcionar a socialização desse saber, a escola também pode instrumentalizar esses educandos para discernirem seu papel de agentes transformadores na sociedade.

No que se refere à educação ambiental, além de ser considerada educação, ela contempla, também, questões ambientais, levando em conta, ainda, que essas se relacionam diretamente com as questões sociais. Concordamos, assim, com Layrargues (2004, p. 7, grifos do autor):

Educação Ambiental é um vocábulo composto por um substantivo e um adjetivo, que envolvem, respectivamente, o campo da Educação e o campo Ambiental. Enquanto o substantivo Educação confere a essência do vocábulo "Educação Ambiental", definindo os próprios fazeres pedagógicos necessários a esta prática educativa, o adjetivo Ambiental anuncia o contexto desta prática educativa, ou seja, o enquadramento motivador da ação pedagógica.

Nesse sentido, compreendemos que a educação ambiental, sob uma perspectiva crítica, consiste numa prática social intencional, que proporciona aos indivíduos condições cognitivas para que, por meio de ações coletivas, busquem superar o modelo de sociedade atual, pautado nas formas capitalistas de dominação e exploração dos homens entre si e deles com a natureza, 
visando mudanças na ordem estrutural de nossa sociedade e nas consequentes relações com a natureza.

Considerando a educação como mediação, Cury (2000) assinala que a educação media as ações que se realizam na prática social permitindo que as ideias que a permeiam (educação), façam parte desse processo e sejam integradas às ações.

Sob o ponto de vista da sociedade, as mediações concretizam e encarnam as ideias ao mesmo tempo que iluminam e significam as ações. No caso da educação, essa categoria torna-se básica porque a educaşão, como organizadora e transmissora de ideias, medeia as ações executadas na prática social. Assim, a educação pode servir de mediação entre duas ações sociais em que a segunda supera, em qualidade, a primeira. Mas também pode representar, como prática pedagógica, uma mediação entre duas ideias, pois a prática pedagógica revela a posse de uma ideia anterior que move a ação. Finda esta última, novas ideias surgem como possibilidades de iluminar a prática pedagógica seguinte. Esse duplo movimento permite entender como, sem essa categoria, a educação acaba formando um universo à parte, existente independentemente da ação. Esta categoria permite superar o aparente fosso existente entre as ideias e a ação (CURY, 2000, p. 28, grifos nossos).

Segundo o autor, a categoria de mediação vincula, de forma mútua e dialética, os diferentes momentos de um todo e, também, supõe que os fenômenos devam ser considerados em conjunto, não havendo o isolamento dos mesmos. "O conceito de mediação indica que nada é isolado. Implica, então, o afastamento de oposições irredutíveis e sem síntese superadora" (CURY, 2000, p. 43).

Saviani (2015), por sua vez, considera que, na pedagogia histórico-crítica, a forma escolar de educação é priorizada por motivos de cunho histórico e teórico-metodológicos e, com a centralidade da categoria de mediação, a educação é compreendida como atividade mediadora.

Dessa mesma forma, consideramos que nos processos que se desenvolvem durante o trabalho educativo, relacionados à temática ambiental e as questões socioambientais, ideias e ações são mediadas na prática pedagógica e na prática social, por meio da socialização de conhecimentos relativos à temática ambiental, que promovam a reflexão de ações, que orientem novas reflexões e novas ações.

Nesse sentido, a educação ambiental, assim como a educação, pode ser mediadora de ideias e de ações executadas na prática social, enfocando conhecimentos e questões relacionados à temática ambiental e aos problemas socioambientais. E, sendo a escola, o espaço principal onde a educação ocorre na sociedade contemporânea, bem como onde a educação ambiental está presente, ela é, igualmente, espaço concreto da realização de mediação.

\section{Procedimentos metodológicos}

O presente artigo resulta de uma pesquisa de natureza qualitativa, realizada na rede pública municipal de ensino de Rio Claro, SP, e, para o desenvolvimento desta, foram utilizados 
como procedimentos de coleta de dados: questionários, entrevistas semiestruturadas, observações e análise documental.

Além disso, como procedimento preliminar norteador da nossa investigação, realizamos um diagnóstico nos Projetos Político-pedagógicos e nos Planos de Trabalho das unidades educacionais da rede pública municipal, objetivando verificar a existência de trabalhos considerados de educação ambiental nas escolas ${ }^{2}$.

Os questionários foram respondidos por todos os gestores da rede pública municipal de ensino de Rio Claro. A partir de sua análise, selecionamos 7 (sete) escolas que atendem o Ensino Fundamental I, que foram investigadas, sendo: 3 (três) escolas, cujas respostas dos gestores se apresentaram consistentes, coerentes e detalhadas, com descrições ou diversidade de atividades e de políticas públicas de educação ambiental; 3 (três) escolas que, nas respostas dos questionários respondidos pelos gestores, não apresentaram conhecimentos sobre políticas públicas de educação ambiental e que também não apresentaram diversidade de atividades para o desenvolvimento da educação ambiental e 1 (uma) escola que, apesar de apresentar algumas atividades diversificadas para desenvolver educação ambiental, na resposta relativa ao conhecimento sobre políticas públicas de educação ambiental, o(a) gestor(a) declarou desconhecer tais políticas, não realizando nenhum comentário sobre o que compreende por políticas públicas.

Após essa seleção, realizamos entrevistas semiestruturadas com o Coordenador Pedagógico de Educação Ambiental da Secretaria Municipal da Educação (SME), com as professoras coordenadoras das escolas investigadas e professores(as) indicado(a)s por tais profissionais, como os que apresentaram um trabalho considerado consistente em educação ambiental, isso é, um trabalho significativo em que se destacaram positivamente entre os demais professores na abordagem da educação ambiental em suas aulas.

Realizamos, também, observações do desenvolvimento de práticas pedagógicas em educação ambiental das professoras entrevistadas e analisamos documentos relacionados ao desenvolvimento da educação ambiental nas escolas investigadas, assim como projetos e/ou documentos relacionados diretamente com as atividades observadas.

Para o sigilo dos nomes das escolas e dos profissionais entrevistados, os mesmos foram denominamos com as letras A, B, C, D, E, F e G, respectivamente.

$\mathrm{Na}$ análise dos dados coletados, após a leitura de Aguiar e Ozella (2006, 2013), Alves -Mazzotti e Gewandsznajder, (2001), Bogdan e Biklen, (1994), Lüdke e André (2015), realizamos algumas etapas que nos pareceram apropriadas para a pesquisa.

Inicialmente, organizamos todo o material coletado. Depois de organizar e fazer uma leitura preliminar, procedemos a uma nova leitura, mais apurada, do material, buscando selecionar aspectos e/ou elementos relacionados aos objetivos propostos em nossa investigação.

Para isso, construímos um quadro para cada procedimento de coleta de dados (entrevistas, observações e análise de documento), em que os trechos dos materiais de cada escola investigada foram destacados com cores diferentes, a fim de verificarmos a frequência desses aspectos e/ou elementos em cada escola e nos diferentes materiais coletados.

\footnotetext{
${ }^{2}$ Cabe salientar que o projeto da pesquisa aqui em pauta foi devidamente submetido ao Comitê de Ética em Pesquisa em Seres Humanos do Instituto de Biociências da Unesp do câmpus de Rio Claro com Certificado de Apresentação para Apreciação Ética (CAAE) n ${ }^{\circ}$ : 36882314.0.0000.5465 e aprovado pelo parecer n ${ }^{\circ} 939.529$.
} 
Os excertos selecionados nos diferentes materiais coletados, contendo aspectos e/ ou elementos referentes às questões de pesquisa, foram lidos novamente e destacados os que apresentavam ideias recorrentes, que fossem similares e/ou se complementassem.

A partir da análise dos dados coletados, e considerando as frequências, afinidades e aproximações dos mesmos, construímos 5 (cinco) agrupamentos, por meio dos quais realizamos a discussão dos resultados obtidos durante a investigação. No processo de construção desses agrupamentos, fizemos uso, quando possível, da triangulação ${ }^{3}$, buscando maior consistência para as análises empreendidas. Neste artigo, apresentamos e discutimos os referidos agrupamentos.

\section{A transversalidade e a interdisciplinaridade no desenvolvimento da educação ambiental nas escolas}

A educação ambiental deve ser desenvolvida no ensino formal, de maneira transversal e interdisciplinar, não sendo uma disciplina específica do currículo, mas permeando as demais disciplinas de modo a integrar-se a elas, conforme prescreve o $\int 1^{\circ}$ do Artigo 10 da PNEA, Lei no 9.795 de 27 de abril de 1999 (BRASIL, 1999), e também o Parágrafo único do Artigo 16 da Política Estadual de Educação Ambiental, Lei no 12.780, de 30 de novembro de 2007, que traz a seguinte redação: "A Educação Ambiental não deve ser implantada como disciplina específica no currículo de ensino, devendo ser inserida de forma transversal no âmbito curricular" (SÃO PAULO, 2007, p. 4).

$\mathrm{Na}$ legislação do município de Rio Claro encontramos essa indicação na Política Municipal de Educação Ambiental, Lei no 4.026 de 26 de fevereiro de 2010, que em seu Artigo $1^{\circ}$, afirma:

- Fica instituída a Educação Ambiental na Rede Municipal de Ensino, como uma prática educativa integrada, de maneira transversal/interdisciplinar, contínua e permanente em todos os níveis e modalidades do ensino formal, na elaboração de projetos educativos, no planejamento de aulas e na análise do material didático. (RIO CLARO, 2010, p. 1).

Cabe ressaltar que a transversalidade diz respeito ao fato de que um determinado tema (por exemplo, o meio ambiente) transita nas diversas disciplinas do currículo escolar. Ao passo que a interdisciplinaridade, conforme Carvalho (2012, p. 121):

[...] não pretende a unificação dos saberes, mas deseja a abertura de um espaço de mediação entre conhecimentos e articulação de saberes, no qual as disciplinas estejam em situação de mútua coordenação e cooperação, construindo um marco conceitual e metodológico comum para a compreensão das realidades complexas. A meta não é unificar as disciplinas,

\footnotetext{
${ }^{3}$ Triangulação é entendida, aqui, como uma técnica usada para se obter maior consistência na análise dos dados. Ou seja, considerando a complementação entre os dados colhidos a partir de procedimentos diversos de pesquisa (entrevistas, documentos, observação etc.).
} 
mas estabelecer conexões entre elas, na construção de novos referenciais conceituais e metodológicos consensuais, promovendo a troca entre os conhecimentos disciplinares e o diálogo dos saberes especializados com os saberes não científicos.

De acordo com Gallo (2001, p. 22), a transversalidade e a interdisciplinaridade, "quando trabalhadas no currículo, [...] complementam-se, possibilitando uma nova dimensão social do processo educativo, que transcende o aprender pelo aprender puro e simples, desprovido de sentido sociopolítico".

Pontuamos que, nos materiais coletados encontramos elementos que apresentam, no contexto das escolas investigadas, a compreensão de que é necessário que o trabalho em educação ambiental ocorra de maneira transversal e interdisciplinar, não constituindo disciplina específica do currículo.

Há professores que entendem que, ao desenvolver um mesmo tema ou assunto em várias disciplinas, esses são abordados de maneira mais ampla, possibilitando que sejam compreendidos em seus diversos aspectos. A Professora C apresenta esse entendimento, ao afirmar que essa é forma com a qual trabalha e obtêm resultados positivos.

\section{[...] Isso é uma coisa que eu sempre fir. E dá muito resultado, porque dai não fica uma coisa estanque, fechada né? Ele tem a visão global. E é muito gostoso. A gente constrói gráficos, a gente faz situações problemas, eles inventam situações problemas com toda aquela temática que a gente estava discutindo. As producões depois, texto informativo pra informar como deve se fazer com o lixo. E a gente desenvolve um texto é, instru- cional, com desenhos pra poder é, verificar como que vai fazer com o lixo. Então assim é, trabalha-se o máximo possivel tudo, todas as possibilidades. Essa é a linha do meu trabalho. [Professora C].}

No entanto, embora haja a compreensão da importância do trabalho com a transversalidade e interdisciplinaridade, há indicações de que não seja frequente, apresentando-se ainda como um desafio.

A interdisciplinaridade ainda é um desafio tá, e ainda nós estamos assim: 'Agora nós
vamos tratar desse assunto'. E trata desse assunto, algumas coisas duram o ano
inteiro como as campanbas, mas falar desse assunto acaba ficando num momento e não
tem esse ir e vir, vamos produzir alguma coisa que seja a mais longo prazo. Acaba
ficando, a campanha continua, mas o tema é trabalhado e naquele ano, né. A água, por
exemplo, né trabalha-se, pronto, vai pra outro assunto. [Professora coordenadora F].

Mesmo não sendo uma prática frequente, constatamos que, tanto nas entrevistas como nas atividades observadas, a intenção em integrar os assuntos relativos ao meio ambiente com outras disciplinas se faz presente, havendo discussões sobre os problemas ambientais e suas consequências.

Os procedimentos utilizados pelas professoras para buscar realizar a integração da educação ambiental nas disciplinas curriculares, assim como a preocupação expressa nos do- 
cumentos em trabalhar o tema meio ambiente como tema transversal, por meio de projetos interdisciplinares, compõem um processo que podemos identificar como mediador das políticas públicas de educação ambiental, uma vez que a indicação de que a educação ambiental seja desenvolvida de maneira transversal e interdisciplinar é, como observado, explícita nessas políticas.

Observamos, no entanto, que nas escolas investigadas a busca por integrar a temática ambiental em diferentes áreas do currículo, embora presente, não é uma prática frequente e contínua. Pois, conforme mencionado pela Professora Coordenadora F, há professores que possuem dificuldade em desenvolver a temática ambiental de maneira articulada entre as diferentes disciplinas e acabam por realizar atividades isoladas, envolvendo a educação ambiental.

Ressaltamos, desse modo, que, embora os procedimentos utilizados por algumas professoras investigadas para buscar realizar a integração da educação ambiental nas disciplinas curriculares, assim como a preocupação expressa nos documentos de trabalhar o tema meio ambiente como tema transversal por meio de projetos interdisciplinares, integrem um processo que podemos identificar como mediador das políticas públicas de educação ambiental, não podemos inferir disso que tal processo seja constante nas escolas investigadas.

\section{O trabalho com projetos de educação ambiental nas escolas}

As Diretrizes Curriculares Nacionais para a Educação Ambiental (DCNEA), presentes no documento das Diretrizes Curriculares Nacionais da Educação Básica (DCNEB) de 2013, indicam que o planejamento curricular envolvendo a educação ambiental, juntamente com a gestão da instituição de ensino, entre outros aspectos, deve promover a realização de:

[...] projetos e atividades, inclusive artísticas e lúdicas, que valorizem o sentido de pertencimento dos seres humanos à natureza, a diversidade dos seres vivos, as diferentes culturas locais, a tradição oral, entre outras, inclusive desenvolvidas em espaços nos quais os estudantes se identifiquem como integrantes da natureza, estimulando a percepção do meio ambiente como fundamental para o exercício da cidadania. (BRASIL, 2013, p. 553).

Assim, o referido documento menciona projetos e atividades com conteúdos relacionados à temática ambiental no desenvolvimento do trabalho com educação ambiental na educação básica.

A denominação pedagogia de projetos, na compreensão de Terossi e Santana (2015) é, contudo, a mais indicada para o desenvolvimento de projetos de educação ambiental por se embasar, não simplesmente, como técnica ou procedimento de ensino, mas numa concepção mais abrangente de posturas pedagógicas. Segundo os autores:

[...] a perspectiva denominada "Pedagogia de Projetos" nos parece oferecer possibilidades mais adequadas para se trabalhar com projetos, principalmente quando buscamos a formação de pessoas críticas, pois possibilita a participação dos alunos em suas etapas de elaboração e desenvolvimento, assim como considera importante a teoria que embasa o método utilizado, bem como a participação ativa do professor (TEROSSI; SANTANA, 2015, p. 81). 
Por meio das entrevistas, observações e dos documentos, notamos que, no desenvolvimento de atividades em educação ambiental nas escolas investigadas, há, dentre outras práticas pedagógicas, a utilização de projetos pedagógicos de educação ambiental.

Nos materiais analisados, observamos que, dentre aqueles realizados pelas escolas investigadas, há os projetos que são propostos pela Coordenadoria de Educação Ambiental da SME e os que são elaborados nas escolas.

Ao realizarmos um diagnóstico preliminar para iniciar a pesquisa, constatamos que dos 53 (cinquenta e três) projetos Político-pedagógicos das escolas municipais, 62\% apresentavam projetos com conteúdos relacionados à temática ambiental e dos 52 (cinquenta e dois) Planos de Trabalho 2014 dessas escolas, aos quais tivemos acesso, 73\% também apresentavam projetos com conteúdos relacionados à temática ambiental a serem desenvolvidos nas escolas. Além desses projetos que são específicos das escolas, outros são propostos pela Coordenadoria Pedagógica de Educação Ambiental da SME, revelando que essa é uma prática recorrente para se trabalhar com a educação ambiental nas escolas municipais.

Durante as análises, um dado que chamou a nossa atenção foi a existência de parcerias entre a SME e algumas empresas, as quais propõem projetos relacionados à temática ambiental para serem desenvolvidos nas Unidades Educacionais. Isso indica que, muitas vezes, as escolas às quais esses projetos se destinam não participam de sua elaboração.

Para Segura (2001, p. 61, grifo do autor) os projetos de educação ambiental enfrentam o desafio de se tornarem espontâneos e de deixarem de ser impostos ou encomendados, pois:

A ênfase na importância da elaboração de projetos na escola não raro assume o papel de 'camisa de força' para os educadores, que se veem empurrados a padronizar sua prática neste formato, atendendo a uma diretriz externa, que quase nunca leva em conta as aspirações dos atores envolvidos (professores e alunos).

De acordo com a Proposta Pedagógica da Escola E, as atividades e projetos que são propostos para as escolas, e que não consideram suas particularidades e especificidades, não contribuem positivamente para a dinâmica do trabalho pedagógico.

Há também no Ensino Fundamental uma significativa demanda no desenvolvimento de campanhas organizadas pelos diversos setores da sociedade civil e militar relacionadas aos mais diversos temas: Reciclagem de Óleo, Descarte de Medicamentos, Educação para o Trânsito, Balonismo, Elektro nas Escolas, Meu dia pede Mele muitos outros. De certa forma, essas campanhas agregam valores e desenvolvem conhecimentos importantes na aprendizagem de nossos alunos, porém a maneira como eles 'surgem' com prazos e características que na maioria das vezes não levam em conta as especificidades de cada escola influenciam, de forma negativa, a dinâmica do processo de ensino-aprendizagem. [Proposta pedagógica escola E, 2013, grifos nossos].

O Coordenador Pedagógico de Educação Ambiental da SME informou que tais projetos são sugestões às quais as escolas podem ou não aderir. Entendemos, no entanto, que, mesmo no 
caso de adesão, se os profissionais tiverem conhecimento da possibilidade do trabalho em educação ambiental numa perspectiva crítica, apesar de os projetos ou demais propostas envolverem concursos, divulgações, campanhas de arrecadação de materiais recicláveis ou competições, as atividades podem ser direcionadas de modo a relacionar as questões ambientais com as questões sociais, realizando reflexões, questionamentos, discussões, críticas e sugestões.

Percebemos que o desenvolvimento da educação ambiental, por meio de projetos, nas escolas investigadas, indica a existência de processos que manifestam a mediação das políticas públicas de educação ambiental no espaço escolar, uma vez que a incorporação da educação ambiental nos projetos pedagógicos das escolas está prescrita em legislações que integram as políticas públicas de educação ambiental.

Contudo, o desenvolvimento do trabalho com projetos com conteúdos relacionados à temática ambiental, nessas escolas, apresenta aspectos que evidenciam contradições presentes nesse processo, a exemplo da questão da autonomia para que as escolas elaborem seus próprios projetos, de acordo com a realidade local; além disso, assinalamos a presença de propostas de projetos construídos em parceria com empresas privadas, que nem sempre contemplam as necessidades e especificidades da escola e de seu contexto.

Pelo relato da Professora C, notamos que demonstra ser contrária a propostas de atividades que não levam em conta o trabalho desenvolvido na escola.

[...] Eu acho que é assim, é trazer coisas sim pra gente trabalhar, mas ver primeiro o que está sendo feito. Porque às vezes se despreza muito o que as escolas fazem. Que já tem um trabalho, já sendo realizado, né? Eu acho de que esse olhar a, às vezes vem, cai muita coisa de paraquedas sabe? Acho que precisa, assim tem que chegar? Tem, porque tem gente que não faz, né? Mas tem que ter esse outro olhar, o lado contrário. Ver o que é que está sendo feito pra complementar. Então não pra, Não, agora você vai trabalhar, isso'. Isso eu não concordo. [Professora C].

No entanto, apesar de manifestações sobre a importância de valorizar o trabalho que a escola realiza, observamos que, na elaboração dos projetos com conteúdos relacionados com a temática ambiental pelas escolas, os problemas ambientais locais, que os profissionais entrevistados informaram existir nos bairros, nem sempre foram contemplados nos projetos desenvolvidos.

\section{A educação ambiental como possibilidade de conscientização dos sujeitos sobre questões ambientais}

Estimular e fortalecer a consciência crítica quanto à problemática social e ambiental consiste em um dos objetivos da PNEA, Lei no 9.795, de 27 de abril de 1999, em seu inciso III do artigo $5^{\circ}$. (BRASIL, 1999).

A análise dos dados revelou que os profissionais entrevistados entendem conscientização como conhecimento dos problemas ambientais enfrentados atualmente e, também, interpretam como necessidade de promover mudanças de hábitos e atitudes frente a esses problemas, tais como: economizar água e energia, separar materiais para serem reciclados e estimular os familiares e outras pessoas da comunidade para fazer o mesmo. A fala da Professora D, durante as atividades envolvendo educação ambiental, expressa essa perspectiva. 
Professora D: Nós somos conscientes do que precisamos fazer. Nós somos conscientes do nosso papel? Todo mundo aqui é? [...] Conscientes de que não pode jogar latinha no bueiro. [...] Nós temos consciência disso? Todo mundo aqui? [...] Temos consciência disso? Nós temos que ajudar. Faz̧er a nossa parte? [Observação da escola D em 14/04/2016].

Em documentos, e também em respostas de alguns profissionais durante a entrevista, a expressão consciência crítica foi utilizada, todavia, pontuamos que a compreensão de conscientização apresentada nos materiais analisados, voltada apenas a mudanças de atitudes e de comportamento em relação ao meio ambiente, sem objetivar uma transformação mais profunda no modelo social e econômico vigente na sociedade, não indica a existência de características relacionadas com a perspectiva crítica.

Dentre os procedimentos pedagógicos utilizados pelas professoras para conscientização acerca dos problemas ambientais, destacamos a confecção de cartazes, de maquetes e sua exposição na escola, visando conscientizar não somente os alunos, mas também seus familiares e a comunidade sobre as questões ambientais, conforme observado na aula da Professora C.

Bom, essa parte do Aterro Sanitário que fala sobre o meio ambiente, sobre a importância de a gente cuidar do espaço que a gente tem. Da gente selecionar o lixo pra ser depositado, pra esse caminhão levar para o Aterro. Isso tem que ter uma conscientização da população e é o que nós vamos mostrar na nossa 'Casa Aberta'. Ensinar o pessoal que não é tudo que a gente vai por na rua, para o caminhão de lixo, pros coletores levarem para o Aterro Sanitário. [Observação da escola C em 12/06/2015].

No desenvolvimento da educação ambiental na escola, e nos processos que permeiam esse trabalho, podemos identificar a mediação das políticas públicas de educação ambiental quanto à intenção de conscientizar ou de formar alunos conscientes sobre os problemas ambientais, como as reflexões em sala de aula, em atividades realizadas, como pesquisas, passeios e discussões sobre observações feitas pelos alunos.

A compreensão de conscientização apresentada pelos profissionais entrevistados, em nosso entendimento, precisa ser ampliada, favorecendo não somente as mudanças comportamentais individuais, mas produzindo um questionamento das causas mais profundas dos problemas ambientais, bem como examinando as possibilidades de ação coletiva na busca por soluções para esses problemas.

\section{Os alunos como multiplicadores dos conhecimentos sobre questões ambientais}

Na Lei no 9.795, de 27 de abril de 1999, que institui a PNEA, o Inciso II do artigo $5^{\circ}$, considera entre os objetivos fundamentais da educação ambiental "a garantia de democratização das informações ambientais" (BRASIL, 1999, p. 2).

A democratização dessas informações pode ser realizada de várias formas e por várias instituições, inclusive pelas escolas, por meio de determinadas ações desenvolvidas com seus alunos. 
Notamos, em alguns dos materiais pesquisados, que há a intenção de que os conhecimentos relativos às questões socioambientais sejam socializados não somente no interior da escola, mas com as famílias e com a comunidade. Nas análises dos materiais, encontramos vários excertos em que os alunos são considerados como agentes multiplicadores desses conhecimentos, não somente para divulgá-los fora da escola, mas, também, para trazer informações e construir novos conhecimentos com seus pares no espaço escolar.

Há, na rede pública municipal de ensino de Rio Claro, um projeto denominado Agentes Ambientais, em que as escolas que participam do projeto, com critérios definidos por elas mesmas, selecionam de 15 (quinze) a 30 (trinta) alunos por período para representá-las como Agentes Ambientais.

Os alunos selecionados participam de capacitações, visitas e outras ações fora da escola, nas quais interagem e constroem conhecimentos sobre as questões ambientais.

A intenção de multiplicar os conhecimentos sobre tais questões, tendo os alunos como agentes, busca concretizar-se por meio de informações obtidas fora da escola e que são trazidas para seu interior e vice-versa, ou seja, por meio da divulgação, fora da escola, de conhecimentos socializados no espaço escolar.

Observamos, entretanto, que os conhecimentos a serem multiplicados pelos alunos, são, muitas vezes, assimilados como mudanças de postura e atitudes frente aos problemas ambientais, como a economia de água e de energia, a separação do lixo, o descarte adequado de óleo usado, de pilhas e baterias e, ações para o combate à dengue.

O objetivo é conscientizar o aluno pra que ele leve isso pra casa dele, e do quanto que é importante que cada um cuide de seu lixo, que a gente preserve o que tem na natureza, não destrua o meio ambiente e preserve aquilo que ele tem. [...] Então. Uma vez. que a gente consegue construir conteúdos atitudinais com eles aqui de tanto falar, de tanto exercitar dentro da escola, a gente percebe desde os pequenos que eles ficam 'atormentando' os pais em casa pra trazerem isso pra cá, né. A gente percebe pelas falas dos pais nas reuniōes que eles levam aquilo que a gente fala aqui e discutem em casa e levam isso pra casa deles. [Professora coordenadora F].

No artigo $2^{\circ}$ da Resolução no 2, de 15 de junho de 2012, que estabelece as Diretrizes Curriculares Nacionais para a Educação Ambiental (BRASIL, 2012) fica evidente que a educação ambiental não deve visar somente o desenvolvimento individual dos alunos, mas acrescentar a esse desenvolvimento elementos que intensifiquem as relações com os outros indivíduos e com o meio ambiente.

Art. $2^{\circ}$ A Educação Ambiental é uma dimensão da educação, é atividade intencional da prática social, que deve imprimir ao desenvolvimento individual um caráter social em sua relação com a natureza e com os outros seres humanos, visando potencializar essa atividade humana com a finalidade de torná-la plena de prática social e de ética ambiental (BRASIL, 2012, p. 2).

A educação ambiental, nessa perspectiva, pretende que os conhecimentos sejam construídos coletivamente, e também socializados, de modo que as ações sejam compartilhadas e as práticas sociais conduzam a uma nova postura frente ao meio ambiente. 
As escolas investigadas apresentaram, em diversos momentos, a importância de socializar os conhecimentos em educação ambiental, revelando a preocupação de que o trabalho desenvolvido atinja mais pessoas do que apenas os alunos.

Esses aspectos revelam que esse processo - que ocorre por meio de projetos, campanhas e de atividades em sala da aula - reforça a tese de considerar as escolas espaços de mediação de elementos prescritos nas políticas públicas de educação ambiental.

Julgamos importante destacar, porém, que, apesar de as escolas proporem que os conhecimentos relacionados às questões ambientais sejam multiplicados por seus alunos para seus respectivos familiares e para a comunidade em geral, esses conhecimentos são, muitas vezes, relacionados à responsabilização individual em relação aos problemas ambientais e para a necessidade de mudanças de atitudes e comportamentos.

Nesse sentido, esses conhecimentos não conseguem promover uma reflexão que permita a associação das causas dos problemas ambientais ao modelo de sociedade atual, à exploração dos homens entre si e desses sobre a natureza.

Reiteramos que há ênfase na economia de água e de energia, separação de materiais para reciclagem, descarte adequado de resíduos, cuidados com elementos da natureza, porém, essas ações são marcadas pela ausência de reflexões com potencial para mediar práticas sociais direcionadas às mudanças estruturais necessárias para minimizar os problemas sociais e ambientais.

\section{O desenvolvimento do trabalho em educação ambiental na escola e sua relação com a comunidade}

Nas Unidades Educacionais investigadas, mesmo com dificuldades, observamos que elas procuram meios para envolver a comunidade no trabalho em educação ambiental. Dentre as dificuldades encontradas, salientamos a inexpressiva participação dos pais e familiares na vida escolar.

Os meios utilizados pela escola para o envolvimento da comunidade se apresentam de diferentes maneiras, tais como: apresentações musicais, danças e peças/esquetes teatrais, divulgando para a comunidade o trabalho realizado, campanhas e arrecadações de materiais recicláveis que envolvem a colaboração da comunidade, participação (mesmo que indireta) da comunidade na elaboração do Plano de Trabalho da Escola e, também, pela preocupação e busca de possibilidades de intervenções nos problemas ambientais nos bairros em que essas escolas estão situadas, procurando soluções integradas da escola, dos alunos e da comunidade.

$\mathrm{Na}$ Escola D, a Professora Coordenadora D, apesar de considerar a pouca participação dos pais e a dificuldade de trazer as famílias para a escola, relata que procura aproximar as famílias por meio das atividades realizadas pelos alunos.

[...] com a educação ambiental, a gente monta murais, os pais quando vem aqui na escola, eles observam o que está sendo trabalhado com relação a todos os temas e porque ainda a participação dos pais é pouca né, então a gente precisa que os alunos levem. Então, às vežes os alunos mesmos que tražem os pais pra: 'Mãe, vem ver o que nós fizemos' pra: 'Tá montado esse mural, é da nossa sala'. E, e assim vai. [Professora coordenadora D].

Observamos que os procedimentos utilizados nas escolas, que buscam envolver os pais e a comunidade nos trabalhos desenvolvidos em educação ambiental indicam, também, 
a escola enquanto espaço de mediação de elementos de políticas públicas. Sob esse aspecto, citamos as Diretrizes Curriculares para a Educação Ambiental para as Instituições Educacionais do Sistema de Ensino de Rio Claro estabelecidas pela Deliberação do Conselho Municipal da Educação de Rio Claro (COMERC) nº 001/2013:

Artigo 18 - As Instituições Educacionais devem elaborar meios de envolver os pais de alunos e a comunidade, buscando o diálogo e a parceria, para juntos, adquirirem conhecimentos sobre as condições ambientais e desenvolverem formas alternativas de utilização dos recursos naturais, promovendo qualidade de vida e convivência saudável entre si e com o meio ambiente (RIO CLARO, 2013, p. 3).

$\mathrm{Na}$ análise dos materiais coletados, verificamos que as escolas investigadas buscam aproximação com a comunidade por meio de diferentes formas, pois essa integração exige que a escola utilize diferentes estratégias; que em algumas escolas há mais participação da comunidade do que em outras, e que a preocupação com essa integração está presente em todas as escolas investigadas.

As escolas, como já reiteramos, procuram, além de divulgar o trabalho desenvolvido com os alunos, manter um bom relacionamento com a comunidade local e propiciar sua participação em conselhos, associações, assim como em campanhas, concursos e promoções propostas pela SME, ou organizadas pela própria escola.

Em nossa compreensão, contudo, embora as escolas se esforcem para promover a participação da comunidade local por meio de diferentes estratégias, envolvendo o trabalho com educação ambiental, essa participação ainda é limitada e pouco efetiva.

Tornamos a enfatizar que essa participação se restringe, principalmente, à colaboração em campanhas de arrecadação de matérias recicláveis, às visitas a eventos da escola, ao comparecimento em apresentações e exposições de atividades dos alunos, nas respostas aos questionários utilizados para elaboração de documentos da escola e, embora algumas atividades contem com pesquisas junto aos familiares, na procura por soluções dos problemas ambientais locais, essas formas de participação não contemplam ações concretas de parceria efetiva entre escola e comunidade.

\section{Considerações finais}

Nas análises dos materiais coletados, observamos que, ao envolver a transversalidade, a interdisciplinaridade e o trabalho com projetos no desenvolvimento da educação ambiental; compreender a educação ambiental como possibilidade de conscientização dos sujeitos sobre questões ambientais; considerar os alunos como multiplicadores dos conhecimentos sobre as questões ambientais e procurar maneiras de integrar a comunidade utilizando a temática ambiental, as escolas desenvolvem processos que se tornam espaços de mediações de elementos presentes nas políticas públicas de educação ambiental.

Tais processos, identificados enquanto indicadores de mediações das políticas públicas, são de importância singular numa perspectiva que necessita, no entanto, ser ampliada. 
Os resultados obtidos com a pesquisa realizada nos permitem concluir que, nas escolas investigadas, os processos que indicam a mediação das políticas públicas de educação ambiental, e os procedimentos pedagógicos pelos quais essas mediações se desenvolvem, efetivam ações na prática pedagógica e na prática social que são direcionadas, predominantemente, para mudanças de hábitos e atitudes comportamentais em relação ao meio ambiente, como o descarte adequado de resíduos sólidos, a separação do lixo e economia de água e energia.

Consideramos, no entanto, de fundamental importância para a ampliação da perspectiva apontada, que a formação inicial dos professores deve contemplar a educação ambiental, capacitando-os, entre outros aspectos, para: adequar o conteúdo relacionado à temática ambiental ao trabalho pedagógico desenvolvido nos diversos níveis de ensino, elaborar e desenvolver projetos com conteúdos relacionados à temática ambiental, desenvolver procedimentos pedagógicos coerentes com os objetivos propostos relacionados à temática ambiental e conhecer diferentes concepções e tendências de educação ambiental a fim de optar pela mais adequada a sua concepção de educação.

Assinalamos, ainda, a necessidade de que a SME promova formação continuada e orientações direcionadas aos profissionais da educação, contemplando reflexões sobre a complexidade da temática ambiental, oferecendo aos educadores a possibilidade de refletirem sobre a relação existente entre as questões sociais e ambientais, assim como o incentivo a desenvolverem com os alunos atividades que efetivem ações na prática social, voltadas para as transformações ambientais e sociais necessárias para o enfrentamento da crise socioambiental, a partir de suas causas e não somente de suas consequências.

\section{Referências}

AGUIAR, W. M. J.; OZELLA, S. Apreensão dos sentidos: aprimorando a proposta dos núcleos de significação. Revista Brasileira de Estudos Pedagógicos, Brasília, v. 94, n. 236, p. 299-322, 2013.

AGUIAR, W. M. J.; OZELLA, S. Núcleos de significado para a apreensão da construção de sentidos. Psicologia: ciência e profissão, Brasília, v. 26, n. 2, p. 222-245, 2006.

ALVES-MAZZOTTI, A. J.; GEWANDSZNAJDER, F. O método nas ciências naturais e sociais: pesquisa quantitativa e qualitativa. 2. ed. São Paulo: Pioneira Thompson Learning, 2001.

BOGDAN, R.; BIKLEN, S. Investigação qualitativa em educação: uma introdução à teoria e aos métodos. 12. ed. Porto: Porto Editora, 1994.

BRASIL. Lei no 9.795, de 27 de abril de 1999. Dispõe sobre a educação ambiental, institui a política nacional de educação ambiental e dá outras providências. Diário Oficial da União, Brasília, 28 abr. 1999. Disponível em: <http://portal.mec.gov.br/secad/arquivos/pdf/ educacaoambiental/lei9795.pdf>. Acesso em: 20 ago. 2015. 
BRASIL. Ministério da Educação. Conselho Nacional de Educação. Resolução no 2 de 15 de junho de 2012. Estabelece as diretrizes curriculares nacionais para a educação ambiental. Brasília, 2012. Disponível em: < http://conferenciainfanto.mec.gov.br/images/conteudo/ivcnijma/diretrizes.pdf>. Acesso em: 15 ago. 2015.

BRASIL. Ministério da Educação. Secretaria de Educação Básica. Diretrizes curriculares nacionais gerais da educação básica. Brasília, 2013. Disponível em: < http://portal.mec. gov.br/docman/julho-2013-pdf/13677-diretrizes-educacao-basica-2013-pdf/file>. Acesso em: 25 fev. 2018.

CARVALHO, I. C. M. Educação ambiental: a formação do sujeito ecológico. 6. ed. São Paulo: Cortez, 2012.

CURY, C. R. J. Educação e contradição: elementos metodológicos para uma teoria crítica do fenômeno educativo. 7. ed. São Paulo: Cortez, 2000.

GALLO, S. Transversalidade e meio ambiente. In: CICLO DE PALESTRAS SOBRE MEIO AMBIENTE, 2001, [Brasilia]. Disponível em: < http://download.inep.gov.br/download/ cibec/pce/2001/15-26.pdf>. Acesso em: 17 ago. 2015.

GONÇALVES, C. W. P. Os (des) caminhos do meio ambiente. 14. ed. São Paulo: Contexto, 2006.

GRAMSCI, A. Cadernos do cárcere. 2. ed. Rio de Janeiro: Civilização Brasileira, 2001. v. 2.

GUIMARÃES, M. Educação ambiental crítica. In: LAYRARGUES, P. P. (Coord.).

Identidades da educação ambiental brasileira. Brasília: Ministério do Meio Ambiente, 2004. p. 25-34. Disponível em: < http://www.mma.gov.br/estruturas/educamb/_arquivos/ livro_ieab.pdf $>$. Acesso em: 10 jan. 2015.

HÖFLING, E. M. Estado e políticas (públicas) sociais. Cadernos Cedes, Campinas, v. 21, n. 55 , p. 30-41, 2001.

LAYRARGUES, P. P. (Re)conhecendo a educação ambiental brasileira. In: LAYRARGUES, P. P. (Coord.). Identidades da educação ambiental brasileira. Brasilia: Ministério do Meio Ambiente, 2004. p. 7-9.

LAYRARGUES, P. P.; LIMA, G. F. C. As macrotendências político-pedagógicas da educação ambiental brasileira. Ambiente \& Sociedade, São Paulo, v. 17, n. 1, p. 23-40, 2014.

LOUREIRO, C. F, B. Complexidade e dialética: contribuições à práxis política e emancipatória em educação ambiental. Educação \& Sociedade, Campinas, v. 26, n. 93, p. 1473-1494, 2005.

LÜDKE, M.; ANDRÉ, M. E. D. A. Pesquisa em educação: abordagens qualitativas. 2. ed. Rio de Janeiro: EPU, 2015.

RIO CLARO (SP). Lei municipal no 4.026, de 26 de fevereiro de 2010. Institui a política municipal de educação ambiental na rede municipal de ensino de Rio Claro e dá outras providências. Diário Oficial [da] Prefeitura Municipal de Rio Claro, Rio Claro, v. 2, n. 222, p. 2-3, 5 mar. 2010. 
RIO CLARO (SP). Conselho Municipal da Educação. Deliberação COMERC no 001/2013. Estabelece as diretrizes curriculares para a educação ambiental para as instituições educacionais do sistema municipal de ensino de Rio Claro. Disponível em: <http:/ /www. educacaorc.com.br/media/biblioteca/7002024/delib_01_COMERC_2013.pdf>. Acesso em: 16 out. 2016.

SÃO PAULO (Estado). Lei $\mathbf{n}^{\mathbf{0}} \mathbf{1 2 . 7 8 0}$, de 30 de novembro de 2007. Institui a política estadual de educação ambiental. São Paulo, 2007. Disponível em: < https://governo-sp. jusbrasil.com.br/legislacao/91905/politica-estadual-de-educacao-ambiental-lei-12780-07>. Acesso em: 27 dez. 2015.

SAVIANI, D. O conceito dialético de mediação na pedagogia histórico-crítica em intermediação com a psicologia histórico-cultural. Germinal: marxismo e educação em debate, Salvador, v. 7, n. 1, p. 26-43, 2015.

SAVIANI, D. Pedagogia histórico-crítica: primeiras aproximações. 8. ed. rev. ampl. Campinas: Autores Associados, 2003.

SEGURA, D. de S. B. Educação ambiental na escola pública: da curiosidade ingênua à consciência crítica. São Paulo: Annablume, 2001.

SEVERINO, A. J. Educação, sujeito e história. São Paulo: Olho d’Água, 2001.

SORRENTINO, M. et al. Educação ambiental como política pública. Educação e Pesquisa, São Paulo, v. 31, n. 2, p. 285-299, 2005.

TEROSSI, M. J.; SANTANA, L. C. Educação ambiental: tendências pedagógicas, fontes epistemológicas e a pedagogia de projetos. Comunicações, Piracicaba, v. 22, n. 2, p. 65-83, 2015.

TOZONI-REIS, M. C. F.; JANKE, N. Políticas públicas para a educação no Brasil: contribuições para compreender a inserção da educação ambiental na escola pública. In: TOZONI-REIS, M. C. F.; MAIA, J. S. S. (Org.). Educação ambiental a várias mãos: educação escolar, currículo e políticas públicas. Araraquara: Junqueira \& Marin, 2014. p. $110-124$.

Artigo recebido em 28/10/2016. Aceito em 04/03/2018.

Contato: UNESP, Instituto de Biociências, Avenida 24 A, n. 1515, Rio Claro, SP, 13506-899, Brasil. 